\title{
IMPORTANCIA SOCIAL DE LOS AMBIENTES MODERNOS DE
} APRENDIZAJE

\section{PRESENTACION}

Por: Carlos Bolivar Bonilla Baquero

Coordinador Postgrado Docencia de la Educación Física. Profesor Titular L ISCOC.

$\mathbf{L}$

os educadores colombianos tenemos un compromiso inaplazable, con la búsqueda de alternativas encaminadas a contribuir en la superación de la crisis generalizada que vive el País. Se debe admitir de manera realista que esta contribución no será suficiente para resolver la crisis pero si necesaria, especialmente dentro del conjunto de opciones civilistas, contrarias a las opciones violentas-militaristas de derecha, centro o izquierda. De la misma manera, se considera que una contribución en este sentido puede resultar significativa desde el aula escolar actual, siempre y cuando los educadores asumamos una actitud favorable a la revisión de nuestro desempeño docente, internalizando concepciones teóricas que posibiliten la construcción de ambientes modernos de aprendizaje. A continuación definiremos esta última expresión.

Ambiente de Aprendizaje. Cuando hablamos de Ambiente de Aprendizaje estamos haciendo referencia a una categoría pedagógica que define la estructura de relaciones en la cual actúan los primeros agentes protagónicos del proceso educativo. Se trata de una categoría que trasciende la concepción tradicional de ambiente de aprendizaje, como espacio fisico del aula y/o como disponibilidad de materiales didácticos.

Esta categoría alude con mayor énfasis a las interacciones y nexos que establecen los Educandos y Educadores entre si, para configurar un cierto tipo de red comunicativa. Interacciones y nexos que están mediados por el uso del poder, del saber, del afecto y, en general, por los valores culturales domi-nantes y no dominantes del entorno social de la institución Educativa.

De esta manera, en el Ambiente de Aprendizaje lo que prima es el tipo de comunicación que se establece a partir de cómo se distribuye el poder para la toma de decisiones, cual es el grado de efecto permitido y propiciado entre los actores, como se concibe y desarrolla el saber objeto de aprendizaje y cual es el tipo de articulación de la experiencia educativa con la cotidianidad cultural de los actores. 
Esta concepción de Ambiente de Aprendizaje corresponde a interpretaciones de la Educación como proceso cultural-comunicativo decisivo para el desarrollo humano, tal como lo expresa Germán rey: "La Interpretación de la comunicación como intercambio de significaciones, la socialización como experiencia de la interacción y la Educación como transacción y recreación cultural' ${ }^{12}$

Así, un ambiente de aprendizaje es también una concreción y una síntesis de posturas teóricas pedagógicas, epistemológicas, sociológicas y, en últimas, un encuentro cultural cuyo desarrollo es esencialmente comu-nicativo.

Ambiente Moderno: Definida ya la categoría de Ambiente de Aprendizaje, conviene ahora aclarar lo que entendemos por ambiente Moderno.

Moderno significa propio de la modernidad, iniciada por acontecimientos tales como la crisis hegemónica de la iglesia por la forma protestante, el renacimiento del pensamiento griego clásico, el auge de las ciencias naturales y el descubrimiento del continente ame-ricano, entre otros. Pero más que acontecimientos históricos, lo moderno es ante todo el ideal filosófico de la libertad, la autonomía y la racionalidad humana como esencias de la especie, de la organización social y de su desarrollo.

12. Rey, Germán. El mundo de la fábula: Comunicación, Ciencia y desarrollo. 1994. pag. 6. En: Trabajo solicitado por la Misión de Ciencia, Educación y Desarrollo a Fundación Social.
Diversos autores coinciden en señalar que con la modernidad la razón humana ocupó el lugar de primicia que poseían Dios y la Iglesia, en cuanto a las relaciones que podían establecer los hombres entre si y con la naturaleza.

Este es el espíritu que ilumina la Revolución Francesa y la proclama de los derechos del hombre.

Desafortunadamente la polifacética racionalidad humana fue reducida con el paso de los años a una sola de tipo técnico-instrumental, asociada a los procesos e instrumentos de producción económica, relegando a un plano marginal otras como la racionalidad comunicativa, estética y afectiva propias de procesos culturales como el Educativo.

A este respecto conviene aceptar la diferenciación entre modernidad y modernización, propuesta por autores como Norbert Lechner: "Por Modernización se entiende el desarrollo de la racionalidad instrumental contraponiéndola a la modernidad en tanto en tanto racionalidad normativa.

La Modernidad apunta a la autodeterminación política y a la autonomia Moral.

Entre tanto, la modernización se refiere a la calculabilidad y al control de procesos sociales y naturales." 13

13. Lenchner, Norbert. Citado por Santana Rodríguez Pedro, En: Modernidad, Modemización y 
Por lo tanto, un Ambiente Moderno de Aprendizaje no se refiere a Modernización Tecnológica, por ejemplo en lus recursus Didácticos, como la propuso la instrucción programada y la Tecnología Educativa-Conductual. Se refiere a la posibilidad de construir una red de comunicación en el aulá, caracterizada por la vivencia reflexiva de una racionalidad cuyo espíritu esté cifrado en la aspiración pedagógicafilisófica de la formación humana. Una formación que reconoce la importancia del encuentro educativo como excelente medio para la construcción de valores. Como, los de Autonomía y Solidaridad, indispensables para la convivencia democrática.

Formación que admite con similar importancia las múltiples racionalidades e inteligencias del hombre, así como también la dialéctica constitución humana que integra lo común y lo diferente en cada uno de los miembros de la especie.

Por estas razones juzgamos como sumamente importante, en el contexto actual que vivimos, intentar un ambiente moderno de aprendizaje que posibilite la formación humana, sin la cual no podremos contribuir a consolidar una conciencia ciudadana requerida para la organización de una sociedad civil crítica, participativa y propositiva; para que ello sea posible es indispensable que el escenario de la experiencia esco-

Gabernabilidad en la Colombia de hoy. Revista FORO No. 14. 1991. pag.5. larizada sea en verdad un modelo de Ambiente Moderno de Aprendizaje. donde se vive y se educa en los principios y valores que queremos formar. De otra manera no ha sido ni será posible.

En esta línea de pensamiento Luis Carlos Restrepo nos propone la concepción de la Ecología Humana: "Todo cambio en las relaciones interpersonales debe pasar por un cambio en las estrategias de comunicación. Dado que el lenguaje es un contituyente fundamental del medio humano, océano en el que nos movemos a diario siendo imposible pensarnos por fuera de él, el trabajo de la Ecología humana no puede ser otra cosa que una autogestión del espacio comunicativo que busca generar un cambio de actitudes en la esfera de la interpersonalidad. La Ecología humana es una Ecología de la cultura y la simbolización, de la lúdida interhumana, de la convivencia y el reconocimiento, del afecto y las estrategias de comunicación". 14

Si no internalizamos nuevas concepciones teóricas acerca de la formación humana y si no podemos hacerlas una realidad cotidiana del aula, el aporte de la Educación a la resolución de la crisis que vivimos será casi nulo.

14 Restrepo Luis Carlos: Ecología Humana, y Autogestión de la interpersonalidad en : Educar para la convivencia, Alcaldía Mayor Bogotá. 1990. pag. 35. 
De allí la importancia de asumir el proceso Educativo como un proceso de interacción y acción comunicativa, según la propuesta Habermasiana. El Filósofo Germano ha diferenciado, sin que sean excluyentes, los procesos de trabajo y los procesos interactivos, asignando un predominio de la acción técnica al submundo del trabajo y un predominio de la acción técnica al submundo del trabajo y un predominio de la acción comunicativa para el submundo de las interacciones socioculturales institucionales. Ya hemos aceptado la concepción de Educación fundamentalmente como un proceso cultural, antes que técnico, por tanto propio de acción comunicativa entre sus actores. En consecuencia es necesario entender que Habermas propone la necesidad de generar situaciones ideales de diálogo, donde haya igualdad de oportunidades en las intervenciones, intencionalidad de llegar a acuerdos para proceder a la acción, veracidad $\mathrm{y}$ honestidad en lo que se dice, compartimiento del mismo código lingüístico $\mathrm{y}$, por sobre todo, ausencia de autoritarismo o coacción entre los hablantes.

Adoptar esta propuesta en el aula es entender que, como lo propone José Alberto Mesa, "Solo en el trabajo racional entre sujetos a través del habla es posible llegar a un entendimiento sobre el tipo de y el sentido de la interacción, posibilitando que el hombre sea el responsable y autor consciente de ella. El hombre no tiene otro medio más que el lenguaje para entenderse sobre algo, y en el caso concreto de la interacción no hay otro camino que el de la acción comunicativa para el hombre tomar conciencia de la individualidad en la intersubjetividad y construir unas relaciones sociales racionales"

Obsérvese que un Ambiente Tradicional de Aprendizaje no se cifra en el tipo de comunicación que se ha expresado aquí, sino en una "comunicación" unidireccional que va del Maestro al Alumno sin interés por la retroalimentación, sin simetría en el uso del habla y sin preocuparse por los consensos, todo sobre la base de una distribución desigual y coactiva del poder, a favor del profesor.

Subyace así en la tradición escolar una concepción de Educación no como fenómeno cultural interactivo, sino como labor técnica productiva. instructiva y trasmisionista, que dista mucho de la aspiración de formación humana antes planteada.

\section{INDICADORES}

\section{CUALITATIVOS DE UN AMBIENTE MODERNO DE APRENDIZAJE}

En la exposición precedente se ha intentado dejar en claro qué se entiende por un Ambiente Modemo de Aprendizaje, ahora es conveniente

15. Mesa. José Alberto. El concepto de interacción en el planteamiento de Habermas. En: Revista Universitas Philosophicas. No. 14. Junio 1990 Bogotá (Colombia) 
sugerir algunos indicadores cualitativos de dicho ambiente, en perspectiva de su posible construcción en la práctica docente.

Retomando parcialmente la propuesta de Ofelia Roldán, Luis Oscar Londoño y Ligia Berrio C. ${ }^{16}$ Se puede hacer la siguiente síntesis de algunos indicadores sustanciales:

\section{EL AULA Y LA ESCUELA COMO ESCENARIOS PLURICULTURALES}

¿Qué tanta articulación, espacio y posibilidad de expresión se permite a las diferente manifestaciones culturales que implican a los actores y al saber objeto de estudio?

¿Se posibilita o no la hibridación cultural del Mundo de Vida que lleva el profesor, los estudiantes y el del contexto de descubrimiento del saber a aprender? ¿o la clase hace abstracción de toda cultura y se centra en el saber a secas?

Un ambiente moderno tiene este dificil reto de articular saber y Mundos de sentido cultural; por no hacerlo así los ambientes tradicionales han generado en los jóvenes la nefasta actitud de desprecio sobre el estudio.

16. Roldán, Ofelia y Otros. Ejecución Curricular y Ambientes de Aprendizaje. En Módulo del Area Pedagógica y Currículo. CINDE. pág. 15-36. 1995.
Un ejemplo, acerca del desconocimiento del Mundo cultural del alumno en la escuela, puede ser el del interés máximo de los adolescentes por el baile moderno. La Escuela, el sitio formativo, no lo permite ni lo contempla; las tabernas, discotecas y bares que son lugares pensados para el lucro mediante la venta de licores constituyen la única opción.

De esta manera, una diversión sana como el baile es asociada y condicionada a las bebidas alcohólicas, mientras tanto la escuela sigue intacta o incontaminada de bailes y fiestas.

\section{EL APRENDIZAJE COMO CONSTRUCCION}

¿Se posibilitan experiencias y reflexiones individuales-colectivas para la construcción estudiantil del conocimiento? o aún se continúa "transmitiendo" el saber de manera pasiva para el estudiante?

Un ambiente moderno de aprendizaje reconoce la postura epistemológica constructivista como base del aprendizaje humano, según la cual el proceso de construcción de conocimientos es dialécticamente objetivosubjetivo y práctico-teórico. Nadie es completamente ignorante, todos poseemos algún tipo de concepto sobre las cosas que nos rodean a partir del cual aprendemos lo nuevo. Aprender, más que memorizar respuestas o condicionar conductas, es construir estructuras de pensamiento, interiorizar operaciones.El error del aprendiz es valioso como 
elemento indicador de sus maneras de pensar, no es censurable, ni corregible por otros, el aprenizaje será significativo si se articula a las expectativas, necesidades, e intereses de la cotidianidad del alumno.

\section{LA PRESENCIA DEL AFECTO}

¿Las interacciones entre los actores Educativos propician y fomentan las expresiones afectivas que dan autoestima, confianza y fortaleza a la amistad y el amor, como sustratos indispensables para un desarrollo humano armónico? o se trata de relaciones mecánicas y superfluas, reducidas al saludo indiscriminado para el grupo ( $y$ esto no siempre) antes de iniciar clase?

Un ambiente modemo evita la represión de la dimensión afectiva y de la expresión corporal, por ello el abrazo, el beso, la caricia, la clase en espacios diferentes al salón-pupitre, preferencialmente en contacto con la naturaleza, son convenientes y necesarios; no prohibidos ni censurados.

Al respecto del divorcio, en los ambientes tradicionales, entre cognición y sensibilidad, Luis Carlos Restrepo comenta: "Si pudiera hacer cumplir una orden semejante, la escuela pediría a los niños que vinieran a clase sólo con sus ojos y oídos, acaso acompañados por la mano en actitud de agarrar un lápiz, dejando el resto del cuerpo en su casa a buen resguardo. "Mirar y no tocar se llama respetar", es una expresión que ejemplifica el deseo del maestro de excluir cualquier experiencia que pueda comprometer al niño en la cercanía y la intimidad". 17

\section{EL MANEJO DEL PODER, EL. CONFLICTO Y LA JUSTICIA.}

¿La toma de decisiones es exclusiva del maestro? ¿Se prohibe, reprime o evita el conflicto entre los actores? ¿Cómo administrar la justicia?

Un ambiente moderno de aprendizaje exige una participación real en la toma de decisiones, por parte de todos los actores. Se busca el consenso sobre la base de los mejores argumentos.

El conflicto se concibe como propio de las relaciones humanas y su tratamiento dialógico como un excelente medio formativo; eludirlo no lo resuelve; reprimirlo genera frustraciones y resentimientos. Según Francisco Cajiao, en los conflictos escolares vale la pena considerar; la forma en que se asume y analice el conflicto y la forma como se resuelven y se tomen las decisiones.

En un ambiente moderno debe analizarse el conflicto con las propias partes comprometidas, oírlas, determinar motivos y circunstancias de los hechos en discusión y, finalmente, tomar una decisión tendiente a que los involucrados corrijan sus errores, reparen

17. Restrepo, Luis Carlos. El Derecho a la Temura Arango Editores pág. 50. 1994. 
daños, se excusen o tengan nuevas opciones de mejores comportamientos. Inclusive se debe aceptar la posibilidad de que el error no sea del educando sino de la norma o de su interpretación; normas e interpretaciones que podrán ser modificadas colectivamente.

Los ambientes tradicionales han hecho caso omiso de esta perspectiva y han asumido una actitud moral heterónoma, según la cual el niño debe obedecer al adulto y a la norma porque sí; cuando ella se infringe se castiga sin el respeto al derecho del debido proceso, pensando en reprimir y no en formar.

¿Cómo formar ciudadanos justos o respetuosos de la justicia en ambientes de injusticia?. Francisco Cajiao dice sobre el particular: "Conflictos escolares tontos mal manejados conducen con frecuencia al maltrato fisico de los niños en el hogar. La arbitrariedad de un profesor al calificar un examen puede llevar a un alumno a abandonar sus estudios. Pero por otro lado existe una reacción oculta de los niños frente a la actuación de las autoridades, que aunque sea inexpresada no deja de crear una actitud de desconfianza y resentimiento ante cualquier autoridad legitima". 18

18. Cajiao, Francisco. Poder y Justicia en la Escuela Colombiana. Editoriales FES, pág. 127. 1994.

\section{REIVINDICACION DE LA DIMENSION LUDICA}

¿Qué tan gratificante, divertida y entretenida es la experiencia educativa?

¿Se concibe aún el juego como algo inútil e intrascendente?

En esta propuesta conviene diferenciar la dimensión lúdica del hombre de sus satisfactores, por ejemplo, el juego; reconociendo que la dimensión lúdica es connatural a la especie en un doble sentido: como necesidad vital de entretención placentera y como potencialidad de producir culturalmente formas de resolver esta necesidad. El juego o los juegos serían satisfactores çulturales de la necesidad lúdica.

El ambiente moderno de aprendizaje debe, no solamente incorporarlos a la experiencia educativa sino, además, tratar de que el aprendizaje adquiera la lógica de lo lúdico: espontaneidad, participación voluntaria, cogestión. autonomía, diversión, flexibilidad normativa y creatividad.

El ambiente tradicional ha sido estructurado sobre la lógica del mundo laboral; Rigidez normativa, obligatoriedad, hipervaloración de la producción material, supervisión, obediencia, etc. 


\section{APERTURA Y FLEXIBLILAD MENTAL}

¿Propiciamos el estudio y la práctica de diferentes concepciones de vida? ¿De conocimiento? ¿De ideologías? ¿De Géneros y preferencias sexuales?

Es necesario adoptar una actitud mental siempre abierta, que permita la posibilidad de asimilación de nuevas o diferentes posturas al respecto de lo que se pretende enseñar. Sabemos que no hay posturas infalibles ni respuestas perfectas o absolutas para un verdadero pensamiento moderno. Existen argumentos y paradigmas mejor fundamentados que otros, desde diferentes miradas.

La rigidez mental para aceptar las diferencias es ajena a la concepción de formación aquí consignada. La flexibilidad mental se verá reflejada en el manejo cotidiano que el profesor hace de metodologías, tiempos, espacios y tipo de opción curricular elegida.

\section{CONCIENCIA ECOLOGICA}

No es posible hablar de un ambiente moderno de aprendizaje en ausencia de una conciencia ecológica. $\mathrm{La}$ indiferencia por la suerte del planeta como ecosistema en riesgo de desaparición, debe transformarse en una actitud de reclamo por aquello que atente contra su equilibrio, tal como ocurre actualmente con las pruebas nucleares de
Francia. Pero igualmente frente a hechos cotidianos supuestamente menores como, el uso de desodorantes con base en la tecnología de los fluorocarbonados, que están destruyendo la capa de ozono - los millares de bolsas plásticas que tapizan los campos de fútbol, al saciar la sed de los jugadores.

\section{PRACTICA DE LA NO VIOLENCIA}

El ambiente moderno de aprendizaje, especialmente en la sociedad colombiana, debe integrar una práctica de la no violencia, una práctica de y para la Paz. Para lograrlo es necesario empezar como afirma Fernando Vela, por el propio educador. Según este autor el educador debe ser de hecho no violento y violento no significa únicamente usar la fuerza física para el castigo material; significa la violación de lo que es constitutivo del hombre como persona y ser social: su expresión, singularidad, autonomía, dignidad, etc.

El ambiente modemo reclama la no violencia como un estilo de vida cotidiano, centrado en el control del impulsivo carácter propio. La educación para la Paz, según Vela, implica una formación en el tratamiento dialógico del conflicto, aceptación de la diferencia de roles, sexos, ideologías. Consumo no depredador de la naturaleza, tolerancia y actitud de desarme.

Ella no implica neutralidad política ni pasividad frente al acontecer social, pues 
incluye en sus presupuestos teóricos la educación para la desobediencia civil cuando las leyes o hechos chocan contra los intereses y las necesidades del bien común $o$ se encaminan hacia el militarismo. Vela afirma: "La educación para el desarme sería un paso más. Aceptando la reflexión de Einstein: " $L a$ Paz no puede conservarse por la fuerza, solo puede ser instaurada por el entendimiento", el esfuerzo del educador se dirige ahora hacia la consolidación de actitudes de paz que incluyen la desposesión de las actitudes violentas y la opción por la supresión de las armas". 19

Desde luego que estos no son los únicos indicadores de un ambiente moderno de aprendizaje pero si son, a nuestro juicio, indispensables para la formación humana y el desarrollo social. Tampoco son indicadores exclusivos del mundo de la escuela, pueden y deberían serlo de toda Institución como, la familia. Donde si deberían ser casi que obligados es en toda Facultad de Educación Universitaria que forma Educadores.

Por otra parte no se encuentran desarrollados teóricamente en profundidad, como es nuestro deseo, por los límites de espacio que exige esta publicación.

No obstante estamos convencidos de la relación directa que existe entre una formación humana basada en los

19. Vela, Fernando. Si Quieres La Paz, Trabaja por la Paz. En: García Estébanez y Otros, Por una Paz sin Armas. Edit. San Sebastián, España. 1984.

planteamientos aquí hechos y el fortalecimiento de una sociedad civil que verdaderamente aproveche los espacios de organización, fiscalización y proposición, que ha abierto la constitución de 1991

Una sociedad civil que se levante con fuerza e independencia crítica frente al Estado y que rechace cualquier opción armada como estrategia para la convivencia; que rechace toda forma de corrupción e injusticia y que invoque la acción comunicativa de los procesos culturales, por ejemplo la Educación. como los medios de construir y fortalecer la Democracia. Una sociedad civil que trascienda los partidos políticos mediante los movimientos cívicopopulares.

Hace unas décadas pretendimos, sin lograrlo, transformar el mundo, la sociedad colombiana, el sistema educativo o al menos, la Institución donde trabajábamos. Quizás la razón por la cual no lo logramos fue, justamente, por que no valoramos ni comprendimos que primero debemos transformarnos nosotros mismos, construyendo ambientes modernos de convivencia.
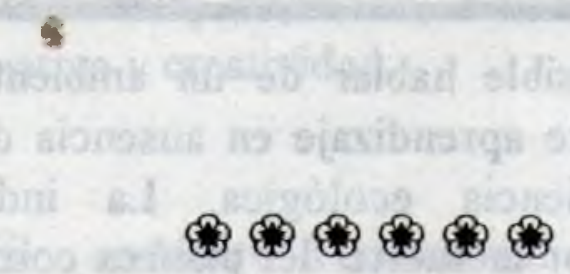